\title{
Doctors' health: stigma and the professional discomfort in seeking help ${ }^{\dagger}$
}

\author{
Antony I. Garelick ${ }^{1}$ \\ The Psychiatrist (2012), 36, 81-84, doi: 10.1192/pb.bp.111.037903 \\ ${ }^{1}$ Tavistock and Portman NHS \\ Foundation Trust, London, UK \\ Correspondence to Anthony Garelick \\ (mednet@tavi-port.nhs.uk) \\ First received 21 Nov 2011, accepted \\ 28 Nov 2011 \begin{abstract}
support services for doctors. Morbidity and the resistance in the profession to addressing their own health needs are discussed. I also explore the principles of bespoke services for doctors, with particular emphasis on overcoming stigma and facilitating therapeutic engagement. I argue that triage is an inappropriate service model of care for doctors.
\end{abstract} \\ Summary I describe the needs for and impediments in provision of psychological
}

Declaration of interest A.I.G. is the Associate Dean, MedNet, London Deanery, and Head of the MedNet Service.
It has been long recognised that medicine is one of the most stressful occupations and psychological morbidity in practising doctors has been estimated at $25 \% .^{1-3}$ The primary problems are depression, anxiety, burnout, alcohol and substance misuse, with high rates of suicidal thoughts and higher completed suicide in female doctors. Suicide rates among doctors are the highest of any health professional group and are more than twice those of the general population. ${ }^{4}$ Yet the mental health of doctors falls into the category of unmet need and the provision of care and support is very limited in many regions in the UK.

The impact of mental ill health on an individual doctor is significant both in personal terms and with regard to possible adverse effect on clinical practice. These issues have been well described, ${ }^{5-8}$ but addressing them properly in terms of the provision of specialist services for doctors has been an afterthought. In the past, doctors with health problems were referred to a colleague out of their catchment area and confidentiality was preserved. There was no organised system of care and, consequently, no empirical data on doctors' health other than anonymised questionnaire studies. This avenue of care, which provided help despite its shortcomings, became unviable with the advent of the internal market, which requires funding approval. The accompanying bureaucratic process was timeconsuming, increased anxiety about confidentiality and thus became an additional impediment to doctors seeking help.

\section{Why are doctors reluctant to seek help?}

There is intense anxiety among doctors seeking help. A more open acknowledgement of psychological difficulties may be detrimental to a doctor's career and this exacerbates the societal stigma regarding mental health problems in doctors. There is also fear in the profession of being

†See special article, pp.104-107, this issue. stigmatised. $^{8}$ The Royal College of Psychiatrists has attempted to address the stigma both in society and in the medical profession through its publications and anti-stigma Changing Minds campaign. ${ }^{9}$ Evidence suggests that doctors frequently do not register with a general practitioner (GP) or do not use GP services when they are registered. The most commonly cited barrier to seeking help is lack of time and pressure of work: long working hours, shift patterns and frequently moving jobs can make it difficult to register with and attend a GP. ${ }^{10}$ These factors, combined with significant fears about confidentiality, are important barriers to seeking help, but just as important are psychological, social and cultural factors. ${ }^{11}$

In depressive states of mind the individual is suffused with pessimism and often views the role of the regulator (General Medical Council, GMC), and also their employer and associated occupational health services, with distrust. This exacerbates common fears of loss of confidentiality and effects on one's career and may be particularly so in a closeknit or small (e.g. rural) community. Other impediments to doctors seeking help are the cultural beliefs embedded in medicine. One common belief is that of being the caregiver, with the fantasy of being invincible and having no thoughts about one's own needs, perhaps equating vulnerability with weakness. It may be that the lack of development of proper services for doctors is a reflection of this professional stigma against personal vulnerability. Doctors as a group are high achievers, responsible, conscientious, driven, self-critical and self-doubting. ${ }^{12}$ These traits in moderation are necessary in medicine, but when extreme, lead to significant anxiety and morbid preoccupation with having not done enough or having failed patients. Doctors tend to take little sick leave and to continue to work when unwell ('presenteeism'), often thinking they would let down their colleagues if they go off sick. ${ }^{13}$ It is likely this situation is now exacerbated by increasing financial strictures resulting in the reluctance to use locums. 


\section{'Doctor patient' - not an oxymoron}

In the face of these anxieties, doctors have hitherto tended to either treat themselves or have informal ('corridor') discussions with colleagues. It is not only that doctors are uncomfortable about being patients. They are also uncomfortable treating colleagues. Frequently, doctor patients report being treated as a colleague in consultations for physical and mental ill health. The anxiety of treating a fellow professional can deskill the doctor. Informal consultation, with no clear lines of responsibility or action, leads to an increase in anxiety, which tends to exacerbate the situation. Doctor patients, particularly those with complex problems, may evoke a range of responses in the treating physician, ranging from bland reassurance to clinical overreaction, and thus they may end up with a poorer standard of treatment than the general patient. An example is to be found in this journal. ${ }^{14}$

\section{Healthcare services for doctors}

In the UK, services for doctors remain patchy and their development rather a struggle to establish on a secure footing. The Shipman inquiry (www.shipman-inquiry. org.uk) focused on patient safety and increased regulation of doctors and did raise some consideration of health issues. There began to be increasing recognition of the importance of the health of doctors, which was reinforced by a report subsequent to the tragic suicide of the psychiatrist Daksha Emson. ${ }^{15}$ In its reports, the National Clinical Assessment Service (NCAS) raised issues of doctors' health. ${ }^{16}$ The recent Boorman review, ${ }^{13}$ in which the economic cost of doctors' ill health has been highlighted, has strengthened the case for the development of appropriate services. The focus is gradually shifting to the health needs of the individual and the growing awareness that an unwell or unhappy doctor is unlikely to be working at their optimal capacity and this is likely to have detrimental effects on patients and the efficient delivery of their care. ${ }^{17}$

In addition, some of the postgraduate deaneries became increasingly concerned about the welfare of their trainees, with an awareness that problems in training could be due to psychological problems in either trainees or trainers. Consequently, the London Deanery and others developed bespoke services where doctors may seek a personal consultation. This supplemented a range of telephone consultation services which had been developed by the British Medical Association several years ago and, more recently, by many of the medical Royal Colleges, including the Royal College of Psychiatrists (Psychiatrists' Support Service) and the pilot Practitioner Health Programme in London.

In North America, organised services for doctors were set up many years ago. The focus of these services was to address primarily the problems of alcohol dependency. They were closely related to the regulator and their primary concern at that time was of patient safety. An unintended consequence has been to associate physician health services with addiction and the regulator. This has not helped alleviate anxiety and stigma in respect of doctors seeking help.

\section{How is a doctor patient different from any other patient?}

There has been little empirical research to describe morbidity in doctors who actually do seek help and such data that there are indicate that doctors come for help late and, consequently, show significant morbidity. ${ }^{18}$ This can be explained by the fact that there has been a paucity of services felt to be confidential and accessible, and by the perceived stigma within the profession and society as a whole. It is important in this context to recognise not only external sources of stigma, but the less easily acknowledged problem of internal stigma of doctors. Having psychological health needs is often seen as a failure and weakness, and conflicts with the still prevalent culture that the doctor can, and should, cope with all the ills of life and work 'physician, heal thyself'.

Current specialist services are reporting increasing referral rates, with psychiatrists being relatively overrepresented. These patterns are open to several interpretations. Is psychiatry becoming more stressful or are our colleagues more open to help? My impression is that the former is the case. The clinical consensus is that the practice of medicine is more stressful, with both peer relationships and trainer-trainee relationships becoming more fragmented as a consequence of complex duty rotas, far-flung rotations and the move to complex team-working, with consequent ambiguity in the location of clinical authority. Supportive relationships and gaining satisfaction from clinical work are becoming harder to achieve, with the increasing focus on financially based outputs. It is frequently felt, and most likely often true, that the protection of the workforce's health is, in general, an afterthought.

\section{Call for specialist services for doctors}

The consensus from the physicians providing services for doctors is that to facilitate a successful engagement in seeking formalised help, services have to be strictly confidential, easily accessible and obstacles such as screening reduced to a minimum. An essential aspect of bespoke services for doctors is the removal of barriers to engagement. ${ }^{19,20}$ This is quite different from the provision of services to the general population, where triage is used at the point of entry, in part to manage demand on services. Doctors who need access to services do not need triage since they generally avoid seeking help; the problem is encouraging them to come in the first place. People tend to suffer for some years before approaching services. Triage is an inappropriate model as it will deter the doctor from engaging. We have found that the most effective method to encourage contact is to offer a face-to-face consultation. Doctors who contact services have significant problems ${ }^{18}$ and should always be offered a consultation, yet if they do engage with services, doctors have good outcomes. ${ }^{19,21}$ In our clinical experience the key is the capacity to establish a therapeutic alliance and to offer an individually tailored programme of care. Equally important is to establish a network of support for those who are more seriously unwell 
and to develop a good relationship with occupational health services who can support a doctor's phased return to work.

Doctors are ill at ease about being patients and in the main they are uncomfortable about treating colleagues. The treating doctor needs to be comfortable about using their clinical authority when treating the doctor patient so there can be clear boundaries and a clear strategy. ${ }^{22}$ It is important in terms of confidentiality that the relationship with the regulator, the GMC, is explicit and that doctors are aware that if there is a fitness to practise issue, the GMC may well need to be informed.

Internationally, there is a large variation about how the regulators of medical practitioners manage health issues in doctors. The GMC has now disbanded the Health Committee, so that all the cases are considered in the round, and if the primary problem is a serious health issue the investigation panel of the GMC will seek a consensual agreement with that particular doctor in terms of future care and management. If that is achieved, the case will not be referred to a formal fitness to practise panel unless there have been serious consequences which will have an impact on patients' safety. In Ireland, the Medical Council has a health committee which carries out an independent assessment with a view to encouraging doctors to seek help, prior to any fitness to practise issues. In the USA, each state has its own medical regulator. By and large, states have a physician health programme, which mainly focuses on drug and alcohol problems. These programmes act as agents for the regulator and are responsible to the health board. There is a large variation internationally in approaches. The main issue under debate is how much health issues should be managed under the broader umbrella of the regulator or how much should they be separate and at arm's length. The consensus from clinicians working in this field is that the most effective way to engage with doctors with health issues at an early stage is separating health services for doctors from the regulator.

In doctors who actually do attend and can engage in a specialist service for doctors, referral to the regulator is a rare occurrence. A particular area where the regulator does get involved is doctors with difficulties who have avoided seeking help or committing themselves to treatment that has been offered. For doctors with drug and alcohol problems, the involvement of the GMC in conjunction with a treatment programme can make a positive contribution to outcome. International data suggest a very high success rate of doctors with dependency issues since the doctors themselves are extremely highly motivated to maintain both their professional identity and livelihood as practising clinicians. This focuses the mind on adhering to treatment programmes and success rates are over $80 \%$ as reported by the majority of specialist services for doctors with addiction problems. ${ }^{23}$

Specialist services for doctors need to be holistic in their approach, to be able to look at the individual health needs of the patient, their work/life balance and the clinical and organisational issues in terms of the environment in which they practise. It is the consideration of the complex interplay between all these factors and the impact on their personal and family life that lead to good outcomes. Doctors' feedback indicates that consultations that lead to greater understanding of their difficulties are valued and confer a greater sense of personal control. ${ }^{24}$ Such services also need to contain anxiety, not only of the doctor attending, but also, if necessary, of colleagues, so that appropriate judgements can be made in terms of work and responsibility. This has become more difficult as employing organisations become more risk averse. Such judgements are complex and, in our belief, require knowledge of medicine from the inside. Hence, they are best delivered by senior physicians with expertise in mental health and extensive psychotherapeutic knowledge.

The development of more specialist confidential services and a more accepting culture within medicine should make a helpful contribution to both doctor and patient care. What I want to particularly emphasise is the importance of the recognition that idealisation of physician invincibility is counterproductive, and that it is professionally important for us to take our needs seriously. ${ }^{25}$ Doctor patients report a great sense of relief at being able to open up about their problems in a safe environment and with a skilled clinician. Such experiences are not only therapeutic in themselves, but also heighten sensitivity in subsequent clinical practice. In addition, the expertise gained from specialist services is a resource to support initiatives by medical educators who are now addressing these issues at both the undergraduate and postgraduate level.

We are very understanding of our patients' difficulties but do not find it easy to accept our own. Medicine is a demanding profession and carries an onerous burden of responsibility, but it can also be very rewarding. It is important to accept that the emotional impact of our work can make us doctors not only stressed, but unwell. ${ }^{26}$

\section{About the author}

Antony I. Garelick is Consultant Psychiatrist in Psychotherapy and Associate Dean, MedNet, London Deanery, Tavistock and Portman NHS Foundation Trust, London.

\section{References}

1 Bergman B, Ahmad F, Steward DE. Physician health, stress and gender at a university hospital. Differential analyses in outcome according to gender. J Psychosom Res 2003; 54: 171-8.

2 Borrill CS, Wall TD, West MA, Hardy GE, Shapiro DA, Carter AJ, et al. Mental Health of the Workforce in NHS Trusts. Phase 1: Final Report. University of Sheffield \& University of Leeds, 1996.

3 Firth-Cozens J. Doctors, their wellbeing, and their stress. BMJ 2003; 326: $670-1$.

4 Department of Health. Invisible Patients: Report of the Working Group on the Health of Health Professionals. Department of Health, 2010.

5 Firth-Cozens J. Interventions to improve physicians' well-being and patient care. Soc Sci Med 2001; 52: 215-22.

6 Firth-Cozens J, Greenlagh J. Doctors' perceptions of the links between stress and lowered clinical care. Soc Sci Med 1997; 44: 1017-22.

7 Frankenhopf AM, Sectish TC, Barger LK, Sharak PJ, Lewin D, Chiang VW, et al. Rates of medication errors among depressed and burnout residents: prospective cohort study. BMJ 2008; 336: 488-91.

8 Department of Health. Mental Health and III Health in Doctors. Department of Health, 2008. 
9 Royal College of Psychiatrists. Mental IIIness: Stigmatisation and Discrimination within the Medical Profession (Council Report CR91). Royal College of Psychiatrists, 2001.

10 Forsythe $M$, Cainan M, Wall B. Doctors as patients: postal survey examining consultants' and general practitioners' adherence to guidelines. BMJ 1999; 319: 605-8.

11 Tyssen R. Health problems and the use of health services among physicians: a review article with particular emphasis on Norwegian studies. Industrial Health 2007; 45: 599-610.

12 Myers MF, Gabbard GO. The Physician as Patient. American Psychiatric Publishing, 2008.

13 Boorman S. NHS Health and Well-Being: Final Report. Department of Health, 2009.

14 Anonymous. Medicine and mental illness: how can the obstacles sick doctors face be overcome? Psychiatrist 2012; 36: 104-7.

15 North East London NHS Strategic Health Authority. Report of an Independent Inquiry into the Care and Treatment of Daksha Emson MBBS, MRCPsych, MSc and her Daughter Freya. North East London NHS SHA, 2003.

16 Berrow D, Faw L, Jobanputra R. NCAS Evaluation, Research \& Development: Analysis of the First 50 NCAS Assessment Cases. National Clinical Assessment Service \& NHS National Patient Safety Agency, 2005.

17 Firth-Cozens J. A perspective on stress and depression. In Understanding Doctors' Performance (eds J Cox, J King, A Hutchinson, P McAvoy): 2238. Radcliffe Publishing, 2006.
18 Garelick AI, Gross SR, Richardson I, von der Tann M, Bland J, Hale R. Which doctors and with what problems contact a specialist service for doctors? A cross-sectional investigation. BMC Med 2007; 5: 26.

19 Meerten M, Bland J, Gross SR, Garelick Al. Doctors' experience of a bespoke physician consultation service: cross-sectional investigation. Psychiatrist 2011; 35: 206-12.

20 Harrison J. Doctors' health and fitness to practise: the need for bespoke model of assessment. Occup Med (Lond) 2008; 58: 323-7.

21 Rø IKE, Tyssen R, Hoffart A, Sexton H, Aasland OG, Tude T. A three-year cohort study of the relationships between coping, job stress and burnout after a counselling intervention for help-seeking physicians. BMC Public Health 2010; 10: 213.

22 Royal College of Psychiatrists. Health for Health Professionals: Enhanced Competencies for Psychiatrists. Royal College of Psychiatrists, 2010.

23 Marshall EJ. Doctors' health and fitness to practise: treating addicted doctors. Occup Med (Lond) 2008; 58: 334-40.

24 Halpert E. Some aspects of the psychoanalytical psychology of physicians. Int J Psychoanal 2009; 90: 1039-56.

25 Rø IKE, Gude T, Aasland OG. Does a self-referral counselling program reach doctors in need of help? A comparison with the general Norwegian doctor workforce. BMC Public Health 2007; 7: 36.

26 Hale R. How our patients make us ill. Adv Psychiatr Treat 1997; 3: 254-8. 